\title{
Entrepreneurial "Blue" Practices for Sustainable Development and Resources Efficiency
}

\author{
Neli Nikolova \\ department of Management \\ Technical University of Gabrovo \\ Bulgaria \\ e-mail:nik_nel@abv.bg
}

\begin{abstract}
The article considers smart solutions for our contemporary sustainable development. The achievements of nature and physics provide innovative opportunities for changing the economy, creating new jobs and added value, and optimizing the resources used. The entrepreneurial way to do this is the blue economy which uses technological innovations based on the perfection of ecosystems where nothing is lost. The proposed practices along with our environment build sustainable models with the help of which business regains its competitive position.
\end{abstract}

Keywords-blue economy, entrepreneurial practice, resources efficiency, sustainable development.

\section{INTRODUCTION}

We live in an unsustainable economic, social and environmental world. Among the reasons that led to the disrupted balance in the socio-ecological system are the mechanical means and technologies used. Environmental deficiencies are symptoms of a continuing crisis in resource provision.

One of the challenges for achieving sustainable development is the creation of new jobs. This could be achieved by using the diversity and perfection of ecosystems and their species. Nature and ecosystems inspire us to change our patterns of production and consumption.

The greatest opportunities for job creation will come from recreating the perfection of ecosystems where nothing is lost. Nature, in all its glamor and diversity, solves many of the challenges to sustainable development in a smart and unexpected way. If we discover the chemistry, processes, structures, and design that life has been developing and testing for millions of years, we will get a lot of new solutions.

\section{EXPOSITION}

Blue Economy offers solutions that are both environmentally friendly and economically beneficial to society. Unlike green economy, which requires considerable financial investment, blue one is looking for a balance. In the entrepreneurial blue practices presented, waste products are used as raw materials, thus reducing costs and harmful emissions for the environment.
Blue economy is built on the following basic principles:

- Satisfying basic human needs with the ones around us

- Using nature-inspired innovations

- Generating jobs and social capital

- Opportunities for realizing entrepreneurial ideas that can achieve more with less

- Generate processes from nature with multiple benefits for society

- Making maximum use of energy and resources to develop sustainable business and reduce the cost for the end user

\section{Specific Principles [1].}

In nature everything is recycled. What appears at first sight to be a waste is in fact a raw material ("food") for a subsequent cycle. For example, the dead leaves falling from the trees turn into soil that feeds a new tree. Such insights can be applied to today's linear production systems, transforming them into closed-loop systems where the limited resources are optimally used and the waste stream is eliminated.

- The solutions are laid down in the laws of physics everything is related to temperature ( $\mathrm{t}$ ) and pressure (p).

- Natural systems transfer substances, energy and materials - there is no waste. Every (sub) product is a resource for something else.

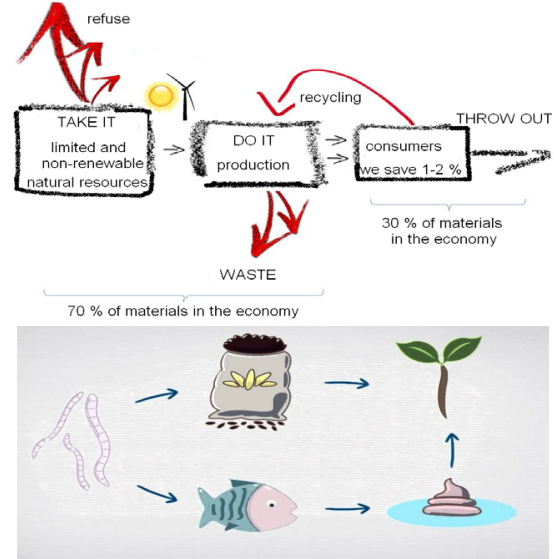

Fig.1. In nature, waste means food

Print ISSN 1691-5402

Online ISSN 2256-070X

http://dx.doi.org/10.17770/etr2019vol1.4114

(C) 2019 Neli Nikolova.

Published by Rezekne Academy of Technologies.

This is an open access article under the Creative Commons Attribution 4.0 International License. 
- Nature evolves from several species to a rich diversity.

- Gravity is the main source of energy - solar energy is a secondary renewable source.

- Water is the main solvent/diluter! - there is no need for complex chemical and toxic catalysts.

- The constant in nature is the change - innovation is constantly happening.

- Nature responds to its basic needs and then develops from sufficiency to abundance - today's patterns of production and consumption function on the basis of resource shortages!

- In nature, everything is biodegradable - everything is a matter of time.

- In the natural systems everything is bound and evolves to a symbiosis.

- In nature, water, air and soils are common - they are many and are free.

- Natural systems share risk - it is this risk that is a motivator for innovation.

- In nature, negatives turn into positives - problems become opportunities!

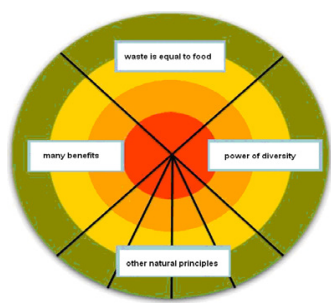

- Nature is looking for large-scale savings - a natural innovation brings various benefits to everyone.

- Nature looks for the optimal in all elements.

According to the UN forecast, the population of the planet will increase by nearly 2.5 billion inhabitants by 2050 . To provide food, Fig.2. Lessons from nature housing and infrastructure to the growing number of inhabitants, new technologies will be needed.

Construction industry has been looking for innovative materials for years to solve problems such as low energy efficiency and better living comfort. [2] One of the most advanced solutions is the use of natural building materials based on hemp and lime. The hemp brick wall has heat insulating properties that exceed several times the performance of the brick and concrete walls at the same thickness, which means that the same building area has a larger living area. Hemp bricks and lime-hemp plaster maintain constant levels of relative humidity in the building, absorbing any condensation. They prevent the formation of mold and create a qualitatively different environment in the room they surround. Hemp walls accumulate heat and evenly distribute it throughout the room. Therefore, in such rooms it will be warm even at low external temperatures. The advantages of hemp concrete are:

- Naturally refractory, waterproof and resistant to termites, pests and mold;

- Long-lasting (weather-resistant);

- Low thermal conductivity $(\mathrm{R}=4.2$ for a wall of a thickness of $300 \mathrm{~mm}$ );

- Dense structure, providing air permeability;
- Hygroscopic material, acting as a buffer for temperature and humidity fluctuations;

- Low carbon footprint;

- Fully recyclable and suitable for reuse;

- Hemp concrete is an elastic material. In case of deformation, uniformly arranged microcracks are formed, which are closed when lime and atmospheric moisture interact.

- Buildings filled with hemp concrete can be demolished without heavy mechanization and serious contamination.

Concrete from hemp is very diverse, as it can be used for walls, floors, roofs, etc. When used as an outside wall, it takes up water and moisture without causing decay or damage to the material.

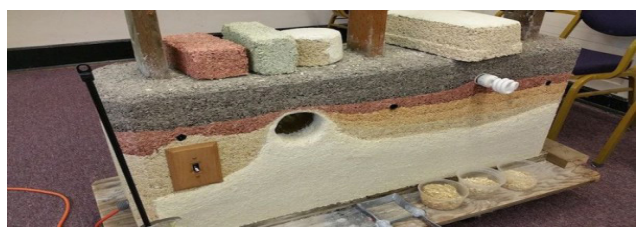

Fig.3.. Concrete from hemp - the supreme material for eco-construction [3]

Life on our planet is an immense source of answers and solutions to the most urgent issues facing human species. The new paradigm that looks at the natural world in quest of innovation and sustainable design is biomimicry. The word comes from the Greek bios (meaning life) and mimesis (meaning to imitate). Biomimicry examines the place of every living being in the complex network of relationships and conditions and looks for its applications in the social and economic environment of our lives. It is connected with taking different technologies from nature and using them to create new things. Examples of innovative technologies are:

- Tunnel drilling machines copy earthworms. Similarly, drilling machines "eat" the ground as they continually move forward, leaving behind a large tunnel.

- Shinkansen high-speed trains in Japan have not only copied the shape of the kingfisher when it penetrates into water, but they also copy their coating which makes them less noisy.
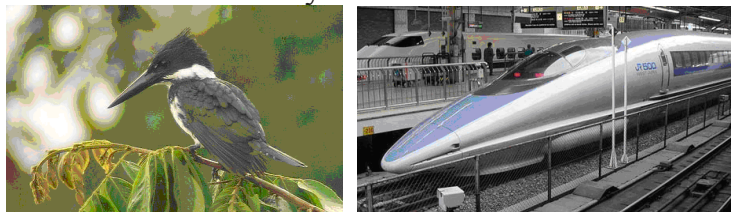

Fig.4.The bird (a) and the high-speed train (b)

Imitation of predatory birds for the design of more cost-effective modern aircraft. They have twisted wings. This amendment was introduced as a result of the observation of birds' flights and it could decrease the consumption of kerosene by $20 \%$.

Nature is our mentor - it is a source of information and inspiration for creativity and ecological design, for the functioning of economic systems based on limited resources for homes that are heated and cooled on their own.

Termites construct mounds that maintain a constant internal temperature due to their structure and interaction with the environment. Architect Mick Pierce uses Termite's principles to design a business building in Hara- 
re, Zimbabwe, which is passively cooled. A \$ 35 million building saves $10 \%$ of the cost in advance and since it is not necessary to buy an air conditioning system. The multi-storey building is heated and cooled only by natural air currents. The economic benefits of this new system are exceptional. Unlike nearby buildings, rents are cheaper due to enerov cost savings.

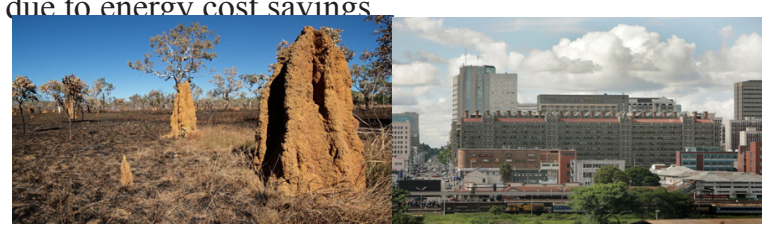

Fig.5. Termitary (a) and Eastgate Business Center (b)

Humpback whales have jagged leading edges. When they swim, water passes through their protrusions and forms a lot of vortices. In this way, whales get a greater lifting force that allows them to tilt their fingers at a great angle without losing their speed, and the protrusions reduce resistance. Researchers apply this principle in making more efficient water turbines. WhalePower develops blades for wind turbines using the same physical characteristics to make its invention quieter and more reliable in winds.

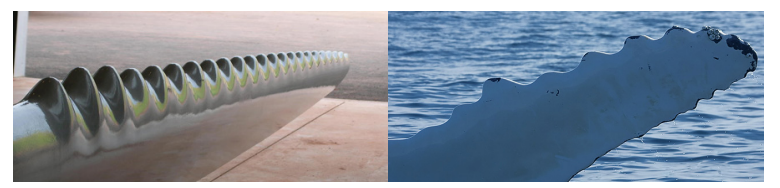

Fig.6. Flipper of back whal (a) and wind turbine blade (b)

Diversity in nature provides strength and various benefits. The most fascinating aspect is people's ingenuity with their ability to use the peculiarities of the surrounding landscape to his advantage. The masterpiece of engineering was the well-organized agriculture run by the Aztecs. They skillfully built ingenious floating gardens, which were small rectangular areas of fertile arable land floating on the shallow lake in the Valley of Mexico. Workers wielded sticks to each other to form giant rafts stretching over $90 \mathrm{~m}$ in length and $30 \mathrm{~m}$ in width. They then collected mud from the pond and piled it on a raft to achieve a soil cover. The rafts were fastened to the lake with ropes attached to mayow trees planted nearby. Between the floating gardens there were channels that allowed the canoes to pass. Water management was vital to ensure good harvest during the year. The Aztecs developed a complex drainage system that includes dams, sluices and canals. The entire garden network stretched over 22,000 acres in the lake. They cultivated crops with which they fed the vast population.

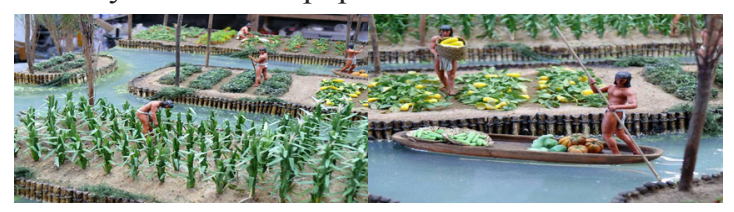

Fig.7. The ingenious floating gardens of the ancient Aztecs . http:// back2nature.rocks/

To create sustainable and productive systems to meet human needs and harmoniously integrate people and land, permaculture is applied. [6] It is a set of methods for sustainable land design. It is based on ecological and biological design principles for human habitats and productive farming systems, maximally resembling natural ones - ecological processes of plants and animals, their food cycles and climatic factors. The elements in the system are considered together with the interactions between them, and the products of one element being a resource for another. In a typical permaculture system, work is minimized: waste is turned into resources, productivity and yields increase and environment is restored. Eco-friendly development approaches can be applied to any environment and scale - from urban residential complexes to rural houses, from small farms to large regions. Permaculture design is based on the care of the earth and people, providing access to all the resources needed for human existence.

According to the UN forecast, the population of the planet will increase by about 2.5 billion inhabitants by 2050. To provide food, housing and infrastructure to the growing number of inhabitants, new technologies will be needed. One of these technologies is vertical aquariumbased farms using LEDs of a specific wavelength to intensify crop growth.

At present, about $80 \%$ of the planet's land on which food products can be grown (vegetables, fruits, grains, meat, dairy products, etc.) is actively processed. The remaining $20 \%$ of potential arable land will not be enough if existing technologies are used to feed the growing population on earth. One of the possibilities for solving this problem is the vertical urban farms for the production of vegetables and fruits. Vertical farms are built where the users of the produce (vegetables and fruits) are located, and on a small area on many floors (racks), production is produced all year round with artificially created parameters: light, nutrient environment, temperature, humidity, ventilation, etc. Thus, annual output per unit area can be increased tens of times, with a significant reduction in production cost and a guaranteed daily supply of fresh vegetables and fruits with almost zero transport costs.

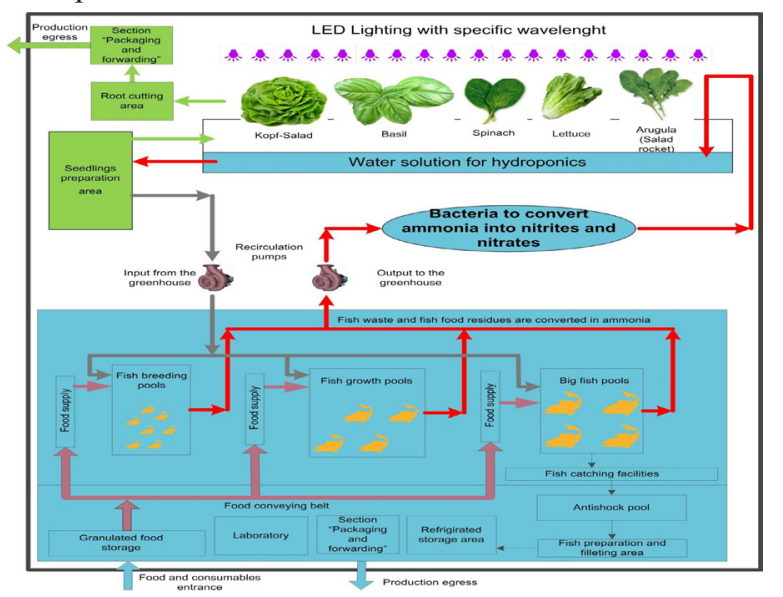

Fig.8. Technological scheme of aquaponics (LEDGROW Engineering Ltd.)

The greenhouse differs from what has been known so far due to the specific illumination of the crops provided by LED strips of a precise radiation pattern and strictly fixed duration of illumination associated with the biological lifecycle of the plants being grown.

High automation of processes reduces the need to employ a large number of additional employees. The greenhouse is adapted to operate under different 
climatic conditions: temperatures from $-300 \mathrm{C}$ to + $550 \mathrm{C}$; humidity from $40 \%$ to $90 \%$; rain, snow and more. The electricity supply to the greenhouse is provided by the power distribution network of the area, by solar panels (autonomous power supply) or by both sources (optimization and reserve of power supply). Water supply is provided by the water supply network.

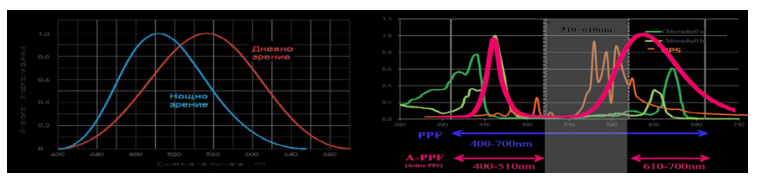

Fig.9. Visible human wavelength (a) and required absorption spectrum for plant growth (b)

The processes in the growth room are realized automatically. For this purpose, the following automated systems have been designed and built:

- Access control system with automatic scanning of the access conditions (chip, card, fingerprint, passage sensors)

- Climate control system for climate control in the room

- Lighting system to ensure the proper illumination of the plants and that in the work rooms.

- Pump station that controls the water flows from the fish pond to the greenhouse and its water basins and vice versa - from the greenhouse to the fish basin;

- Parameter control system of the nutrient aqueous solution.

Within the second stage swimming pools are envisaged for fish breeding. This stage is a major knot in the process and converts the technology from hydro to aquaponics. Aquaponics combines aquaculture and hydroponics: Fish waste provides an organic food source for plants and plants appear a water filter. Aquaponics also has a third component: microbes and composting red worms. Microbes and worms convert ammonia (from fish waste) into nitrate, and nitrates (and solid waste) into a vermicompost (a compost produced from some kind of worms), a source of plant food. While hydroponics does not solve many of the problems of traditional farming (such as weeds, the amount of water required, insects in the soil, other pests that feed on leafy vegetables, mainly fertilizing and composting methods), it still needs "careful application" and "human-made nutrients". Aquaponics only needs fish (along with careful observation). Aquaponics is also a safer way to grow food.

The method of building a farm that combines crop (farm crops) growing and fish breeding in an interconnected cycle (mutual exchange) has been known since ancient times. The name "aquaponica" has been suggested by scientists from the University of the Virgin Islands as a result of years of research. This name reflects the combination of two progressive technologies: "hydroponics" - growing plants not in soil, but in aquatic environment and "aquaculture" - growing fish, crabs, shrimps, mussels, etc. in a well-organized system. A number of observations and later experiments have shown that plants can only be grown in an aquatic environment without the need for soil. At the same time, if fish are kept in the aquatic environment, a double effect is obtained: the waste from fish breeding appears to be an excellent nutrient medium for plants submerged in the aquatic environment. Furthermore, plants are an excellent filter, leaving the waste from fish on their roots and thus purifying the water in the pool. Plants are fed by products extracted from living organisms (potassium, nitrogen and phosphorus compounds, carbon dioxide, etc.) and naturally purify and enrich with oxygen the aquatic environment. The production process eliminates the use of chemical fertilizers and the need for their dosing and soil treatment. The chemical process of treatment and purification occurs naturally in a closed loop and does not require the use of synthetic chemicals. Aquaponics imitates the natural water circle in nature.

The symbiosis between growing plants and fish in a common aquatic environment unexpectedly leads to intensification of plant and fish growth, resulting in a closed ecosystem. Another feature of hydroponics (a constituent part of aquaponics) is that plant cultivation does not require land and its farming, and plants grow in the aquatic environment. This makes possible the development of the greenhouse in a vertical direction and the plants themselves are grown in vertically spaced water channels. Thus, a unit of land is multiplied by a larger production. The combined cycle of growing plants and fish is always more effective than split farming and gives a larger amount of market output from plants and fish.

Purifiers and a mechanical filter system are used to treat water from solid waste and particulates. Denitrification in "aquaponics" occurs naturally - a balanced activity of plants and bacteria and only in extreme cases it requires additional cleaning with expensive carbon filters.

Areas in the fish breeding department are made up of modules whose size is typified and is determined by the type of fish grown and the amount of desired end-ofday catches. The modular building of the room allows you to breed and grow different types of fish according to the needs of the market in different modular pools. It is permissible to mix different populations if there is nonconflict cohabitation.

We will also look at some practical ideas for achieving a sustainable urban environment.

New research and technological advancement allow farmers to find new ways to grow food as effectively as possible. In some cities, such as Chicago, green roofs are even part of the city's common sustainable plan. Specifically in Chicago there are about 359 roofs with vegetation.

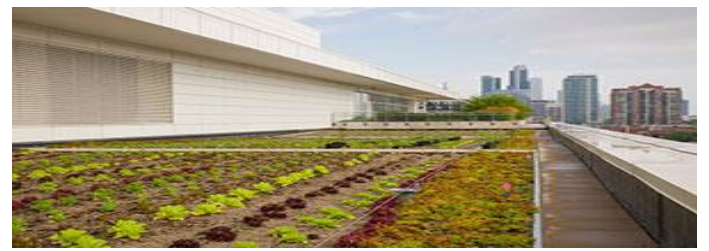

Fig.10. Chicago Botanic Garden's McCormick Place West Rooftop Garden

Per unit area, field yields are often larger than areas grown under traditional methods. Roof farming not only provides fresh food to the cities but it also reduces energy cost of buildings and contributes to cleaner air. 
In addition, roof farming helps society by providing jobs and giving people a new category of public spaces (places to communicate). In addition, roof farms keep rainwater (diverting drainage water from sewage systems) and focus on food production, thus eliminating the need to transport fresh food from a neighborhood to a neighborhood.

Many views on nature in cities draw attention to the importance of the link between green and blue infrastructure in densely populated areas. Successful people-to-people reconnection will have a positive impact on their values and will ensure the protection of ecosystem services.

Rich natural diversity gives birth to unique entrepreneurial opportunities that become the backbone of modern economics. Bulgarian youth offer an innovative concept of an eco-restaurant built and furnished with natural and recycled materials. [4] The restaurant generates the electricity needed for its operation through solar panels and purifies the water used by means of a special system. The restaurant serves dishes prepared exclusively from natural products supplied by local producers. Young entrepreneurs also organize monthly educational eco-courses in the restaurant. They also offer home delivery with cyclists.

Another entrepreneurial idea of young people is to create a gym with appliances that allow the energy of mechanical movements in the course of training to be stored and turned into electricity. A large dashboard will be placed in front of the gym, which will show the amount of electricity generated by customers during the month and will calculate how much $\mathrm{CO} 2$ emissions are saved through their involvement. The most active exercisers who use these devices will receive special discounts.

The idea of eating our own waste sounds disgusting and repulsive. In nature, however, this is a natural process: the "waste" of all living organisms is broken down into organic compounds that feed the soil and plants, and they in turn feed us humans. The French architectural company "Chartier-Corbasson" uses this "organic" metaphor to construct a building from panels made on site from the plastic waste collected and separated by its inhabitants. According to Jetson Green, a popular American blogger for sustainable construction, the creators of the "growing" building have calculated that plastic waste collected over a year would be enough to complete the building's facade.

There are various ideas and approaches for developing intelligent solutions. The Eastern and Western coasts of the United States offer several indicative practices for "intelligent" urban management systems in action. For example, in San Jose, Calif., also known as the Silicon Valley capital, Intel has sponsored an urban network of sensors to collect data on air quality, noise pollution and traffic flows. Thus, in case of accident, the responsible municipal authorities can quickly respond, redirecting traffic and timely sending information to residents so that they can decide to use different modes of transport (such as cycling instead of driving).

To the east, New York could boast of a massive program to improve the energy efficiency of municipal housing, which uses intelligent energy-saving technology and thus saves valuable financial resources in the city's treasury. Intelligent Urban Systems are underway in the continental part of the United States. To live in a sustainable way, we need to focus on practices that pay close attention to how we consume resources rather than to the development of technology.

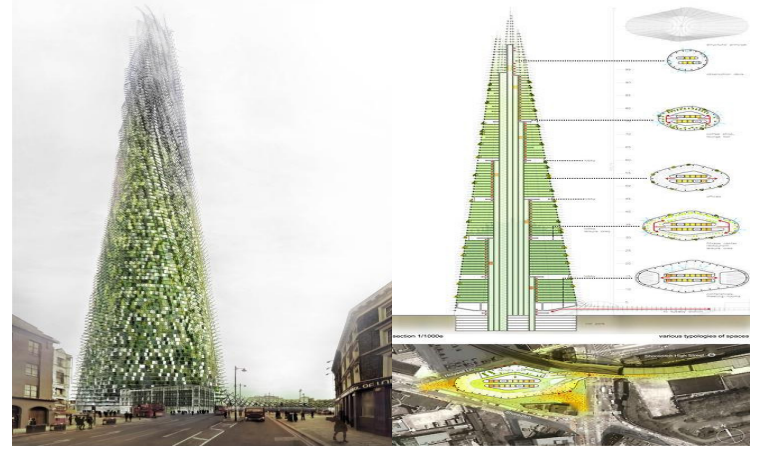

Fig.11. Sketches of the London Organic Skyscraper project. Photos: Shutterstock, Chartier-Corbasson

The production of the world's blue economy is currently estimated at around EUR 1.3 trillion and is expected to double by 2030. Bulgaria, together with the Mediterranean and Black Sea countries, is involved in building a cluster network as part of European development projects of the maritime industry, aimed at stimulating the "blue" economy. [5] Investing in "blue" projects is becoming an important driver of prosperity and job creation in coastal areas. The participants are committed to solving the most pressing problems of the world's water areas. The European Commission proposes a transition to an economy based on better design, recycling and reuse of products that will contribute to cleaner oceans.

The seafaring and maritime sectors provide jobs for 5.4 million people now and contribute a total gross value added of around $€ 500$ billion a year. By 2020, they should increase to 7 million people and nearly 600 billion euros respectively. Coastal and maritime tourism is the largest sea-related sector in terms of gross added value and employment and is projected to increase by $2-3 \%$ by 2020, according to a study by the European Commission. Within a 10-year period - from 2010 to 2020, cruise tourism is expected to create 100,000 new jobs. With a total budget of $€ 6.5$ billion for the period 2014-2020, the European Maritime and Fisheries Fund supports EU coastal communities to develop their economies, create new jobs and improve the quality of life on European shores.

The market realization of technology for energy generation from waves and tides will be improved by reducing technology costs. According to expert estimates, the total annual turnover in marine mineral resources is expected to increase practically from zero to 5 billion in 2020 and to 10 billion in the period up to 2030. By 2020, the blue "Biotechnology must start supplying mass markets for cosmetics, food and pharmaceuticals, chemicals and biofuels. The Coordinator of the European "blue" economy is the island state of Cyprus. The trend is to build the island as a European Center of Excellence in Marine Research, Innovation and Technology. The future innovation and technology center of excellence will 
stimulate Eastern Mediterranean partnerships in scientific and business research in the blue economy sectors such as maritime transport, coastal and marine tourism, aquaculture development, energy sector.

"Blue" growth is a modern multi-faceted framework based on the main axes of sustainable development - economy, society, environment, and partnership. Under the "Blue Career Center" project on the Eastern Mediterranean and the Black Sea, the first European Qualification Center for blue graduates is being built. It will be located in Cyprus with offices in Bulgaria, Greece and Romania. Its goal is to increase employment in key blue sectors in the region, such as maritime transport and shipping, shipbuilding and ship repair, cruise and sea tourism, aquaculture, offshore oil and gas exploration. The center will attract young people to train, qualify and retrain them thus preparing them to become prospective "blue" specialists. The goal of another Blue NET project is to create a network of sea clusters for "blue" growth in the Mediterranean, Adriatic, Ionian and Black Seas. In this way, cooperation between maritime clusters in the field of research, innovation and competitive growth of enterprises directly linked to European maritime policy and the "blue" economy will be promoted.

\section{III.CONCLUSION}

Nature has been perfectly designed for billions of years. As we learn lessons from nature, we can reform our society by making it richer and more varied, more beautiful, and cleaner. The future of limited resources has urged lots of leading corporations to turn to teams of biologists and designers to find the solutions they want in the natural world. According to the cradle-to-swing model, if designers integrate the intelligence of natural systems, such as substance cycling and vastness of solar energy, they will be able to create products, production systems, buildings, even regional plans which could help nature and industry co-exist without interfering each other. Our current consumption and waste generation system can become a source of products and services that are both environmentally, socially and economically useful. By rediscovering our industrial systems and approaches, we can stimulate innovation that provides sustainable development and prosperity.

\section{REFERENCES}

[1]. Ignatova, Milena. Blue economy [Online]. Available:https:// ede.unisofia.bg/EDE2013/ppt/Ecosystem europe Final.pptx [ Accessed: March. 15, 2019]. [2] http://belchinski-izvor.com/ [ Accessed: March. 18, 2019].

[3]. Project "Return to Nature". [Online\}.Available: http:// BACK2NATURE.ROCKS/ HEMP OF HEMP IN CONSTRUCTION, 2019 [ACCESSED: MARCH. 15, 2019].

[4]. https://www.capital.bg/specialni_izdaniia/obrazovanie/

[5] http://3e-news.net/eu Announces Nearly EUR 3 Billion Investments in the Blue Economy Author: Branislava Bobanac, Cyprus [ Accessed: March. 19, 2019].

[6] http://back2nature.rocks/permanual lifestyle [Accessed: March. 8, 2019]. 